\title{
Design and Integration in E-Commerce Website Based on Framework Technology
}

\author{
WANG Anbao* \\ School of Computer and Information, Shanghai Second Polytechnic \\ University, Shanghai 201209, China \\ wabhappy@163.com
}

\author{
XU Jie \\ School of Computer and Information, Shanghai Second Polytechnic \\ University, Shanghai 201209, China \\ xujiesspu@sina.com
}

\begin{abstract}
With the rapid development of network technology, the Web applications are used more widely, and the higher requirements on the Web system has been pursued by many people. The web applications should become more simple and convenient; also it requires some new internal adjustments in the Enterprise. The techniques of struts2, spring and the Hibernate are used in this paper, and these three kinds of lightweight frames are very popular at present, also the Ajax technology is introduced in our work to implement the development. According to the practical demands of the Back-state management of the B2C Shopping Mall and Inventory management system, this two systems are integrated, and these three framework technologies and Ajax technique are integrated which can in accordance with J2EE three-tier structure as well, finally the framework for Ajax+SSH (Struts+Spring+Hibernate) is realized.
\end{abstract}

Keywords-Struts2; Spring; Hibernate; Ajax; Back-state management; Inventory management system

\section{Introduction}

With the impulse of advancement for network technique and the rapid development of electronic commerce, online shopping has become the latest consumptive mode for consumers, particular for our younger generations who are more accept new concept and tend to pay more attention to it.

In consequence, more and more businessmen establish online malls and make this novel shopping concept accepted by consumers.

However, as for these online malls evolved from traditional malls, there are some redundant, even conflict issues existed in online and offline data management and its process. Especially, it is quite important for the adjustments between the former purchase-sell-stock management system and the latter Backstate management of the online shops, which has higher requirements for the output of the enterprise workload, the integrity and timeliness of the data.

In the past, the client/server architectures are adopted by the purchase-sell-stock management information system, which divides application into two parts. One is the server which is responsible for data management, and the other one is the Client which engages in the interaction with manager. As we known, the client/server architecture is has reflected the superiority, the Inventory management system's upgrade also has been put on the agenda. The improved model and the Back-state management of online mall are very similar, and this will give us opportunities on the integration or mutual expansion between them. The purpose of this paper is to design an online store Back-state management system with the Inventory management system in order to reduce unnecessary data's duplication for input and output and ensure timeconsistency between the two systems described above.

\section{Related techniques}

The purpose of this paper is to construct online mall inventory management integrated system using the concept of purchase-sell-stock management system.

The current three open-source frameworks and Ajax technique are used in our research. Struts serves as a MVC pattern of framework, which separates business logic and data performance effectively, optimizes the system structure, and improves the system extensibility as well. Spring is a lightweight J2EE application framework, and it reduces coupling degree between systems effectively through the reverse control characteristic. Hibernate is an open-source persistence layer framework, and it reduces the complexity of database development and improve the portability of the system with the use of JDBC package. Finally, Ajax combines several technologies, it promotes the user experience through asynchronous refresh and optimizes data transfer between the browser and the web server, more importantly, and it also efficiently reduces the unnecessary data round trip and bandwidth consumption.

These three frameworks and Ajax technology are integrated in accordance with J2EE three-tier structure, it forms the framework of Ajax + SSH (Struts + Spring + Hibernate) and the framework is used in the development of online mall backstage management system. Spring is responsible for the work of business logic layer, which implements the application system with the business logic for the transaction and other functions. The presentation layer can be implemented in the technique of Struts, such as page displaying, responding to users' requests etc. The mainly task of Hibernate is in the data persistence layer, such as completes the interactive function with database. In addition, we will use technology of Ajax to optimize the JSP page in the framework, and with the helping of the local refresh technology to manage the objects in one page, so as to avoid the frequent jump between more pages and make the system run more smoothly. 


\section{The Integration between Struts and Spring Techniques}

There are various methods to integrate Struts and Spring, three of them are very popular, which are Spring's ActionSupport, Spring's DelegatingRequestProcessor and Action's full authority Agency used in Struts. The last one is considered the best of the three.

The Struts' Action can be entrusted to the Spring framework so as to decouple the code, therefore the struts' application can take advantage of the features used in Spring. Moreover, once Spring controls the Struts Action, it can be used to add more vitality to the Struts Action. The control of the procedure is as follows: Firstly, registered plug-in of the Spring in the struts-config.xml file. Then, set type attributes of the action as org.springframework.web.struts.DelegatingActionProxy, the action is delegated to the Spring. Finally, a path attribute of the action tag corresponding to a bean are configured in configuration file applicationContext.xml of Spring.

\section{The Integration between Spring and Hibernate}

The file hibernate.cfg.xml is the most important configuration file of Hibernate. The classes which need persistency and some related global properties are defined in this file, Spring does some encapsulation and interface conversion to Hibernate through the class of LocalSessionFactoryBean, in this way, and then we can use unified method to deal with Spring and Hibernate. At the same time, it also provides a global SessionFactory. In this paper, we will adopt the methods of putting SessionFactory into HibernateTemplate to make the integration between Spring and Hibernate.

The key is that the basic resources which Hibernate needs are provided and injected by Spring. Hibernate creates the DataSource required by SessionFactory, the Session which is necessary for executive persistence and the affairs control which is essential for accessing to the persistence layer access are also created by the Hibernate. These logics which are controlled by the code originally had to be controlled by Spring as a Spring bean container now. Spring manages SessionFactory by applicationContext.xml, and does configuration management of the connection between the SessionFactory and the database by using applicationContext.xml.

According to the description above, the structure of Struts, Hibernate and Spring is displayed in Fig 1. The frames are divided into three layers which are the Presentation Layer (web layer), Business Layer and Persistence Layer. Each frame is responsible for the realization of one layer: The Presentation Layer uses Struts, Spring is used in the Business Layer, and Hibernate is used in the Persistence Layer. Each layer in the application has a clear responsibility, each application layer is independent, but it keeps consistency with each other. These frame levels in a loose coupling effect of each other and do not take the low-level technical details into consideration.

The application of the technologies in Ajax
Due to the fact is subjected to HTML, the B/S application cannot use abundant effects to display the data just like the $\mathrm{C} / \mathrm{S}$ application, any interaction operation with the server are all required to refresh the page, this means that it needs 2 to 5 seconds delay, which leads to poor users' experience, however, introducing AJAX technique in the web applications based on J2EE can well solve these problems. In this mode, the data which was sent directly to the user performance layer was change to return the available data to Ajax Engine. These data includes plaintext, xml and other formats, the only requirement is that Ajax engine can understand and parse the data, the details is displayed in Fig 2.

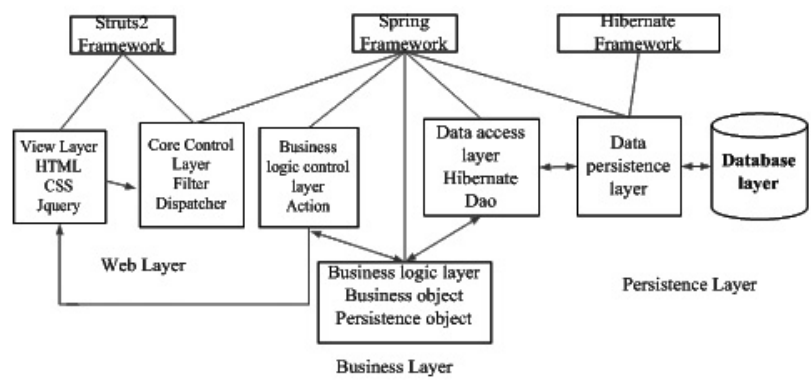

Fig 1. The framework of Struts, Hibernate and Spring

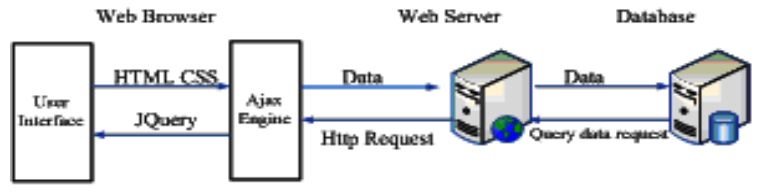

Fig 2. The application model of the Ajax web

\section{Analyses and Design}

After researching the current disconnection between the existing website backstage and purchase-sale-exist management system, the following defects are discovered as follows, Inefficiency, low speed of processing, data transmit not in time, inaccurate, duplication of labor and causing data inconsistencies and so on. The defects have constrained the managers' creativity, and it is difficulty to keep up with the changes of modernization market. However, through the integration of the applications between the techniques of Ajax and $\mathrm{SSH}$ framework, we can combine the characteristics of B2C online mall, make some improvement in system design. The conception is described as follows.

First, because the web mall's foreground and background has a very close relationship, there are some important modules in the mall's foreground, which are web news bulletin, the part of merchandise display, website shopping module, web users' module and website commodity comments module etc. The detailed modules are described in Fig 3.

As shown in Fig 3, these five parts are closely related with the background, and will be reflected in the background one by one, they are news bulletin management, merchandise management, sales management, membership management and commodity comments management. Among them, the 
shopping module and commodity display module are the most crucial parts of the purchase-sell-stock management system, and also the relation is the closest of all. It is difficult to integrate back-state management and purchase-sell-stock management system. The following will focus on this part and introduce in detail.

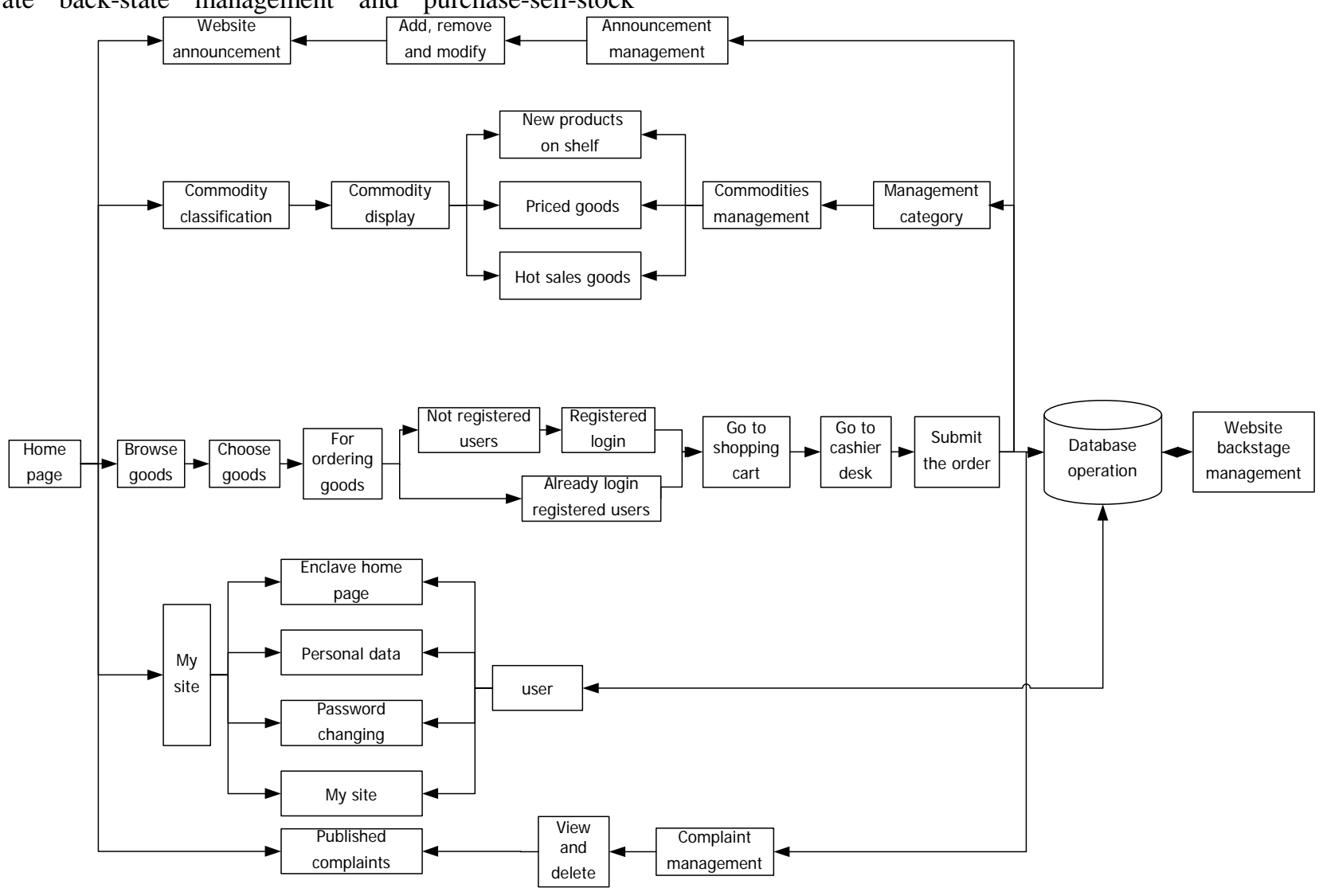

Fig 3. The detailed modules

The relationship between back-state management and purchase-sell-stock management system includes six parts. Firstly, when the registered members complete the shopping process, the data will enter into the sales management module and order management module, and the best sellers list is worked out. Secondly, after registered member confirms the receiving information, then the data will enter into the order management module and inventory management module. Thirdly, after registered member collect merchandise, then the data will enter into the sales management module, and generate preference list. Then, after registered member comments merchandise, then the data will enter into the sales management module, the management module analyses information and improves commodity procurement and sales plan. Again, when procurement department have new commodity, sales management will put commodities on the shelf, and generate latest products. Finally, if some goods is in a large inventory, after approval by related department, the sale department generate Special sale list.

There are four parts in business models, which are purchasing management, sales management, inventory management and financial management. The analyses of their relationships are as follows.
There are three relationships between inventory management and sales management. Firstly, sales management apply to put the goods on the shelves, compare selling quantity and inventory quantity, then according to the difference value and the stock warning level to determine further action. When the difference value is higher than the stock warning level, execute sales outbound operation, at the same time reduce warehouse inventory, at last salesmen put the commodities on the shelves; when the difference value is lower than the stock warning level, by implementing the above strategy and the purchasing information was sent to the purchasing department, and the information content is drew up by the sales department and inventory management departments together. Secondly, the sales department put the goods off shelves, off-the-shelf products will be returned to the inventory department, and they will do in-stockroom operation according to the commodity attribute (such as period, product category). Thirdly, the inventory department put forward outbound sales application to the sales department under a certain conditions (such as near the validity or other outbound cordon).

There are three relationships between inventory management and purchasing management. Firstly, the inventory department put forward purchasing application, the purchasing department and the financial department executes procurement operation according to the order information. 
Secondly, the purchasing department issues the purchase notice, and the inventory department executes commodity input operation. Thirdly, the inventory department issues a return outbound notice and executes goods delivery operation, and then purchasing department will negotiate with suppliers.

There are two relationships between order management and inventory management. Firstly, after the customer complete the payment process, order department take orders operation according to order information and the follow-up logistics is carry on also, and then inventory departments carry out goods delivery processing. Secondly, after the customer receives the goods, if problem appears and the sales department agrees to return, and then the inventory management executes the handling of return goods.

After the above analysis, simple purchase-sell-stock management system was joined into online background management system as an expansion, and a new website backstage management system is created. The summary of each module is displayed in Fig 4.

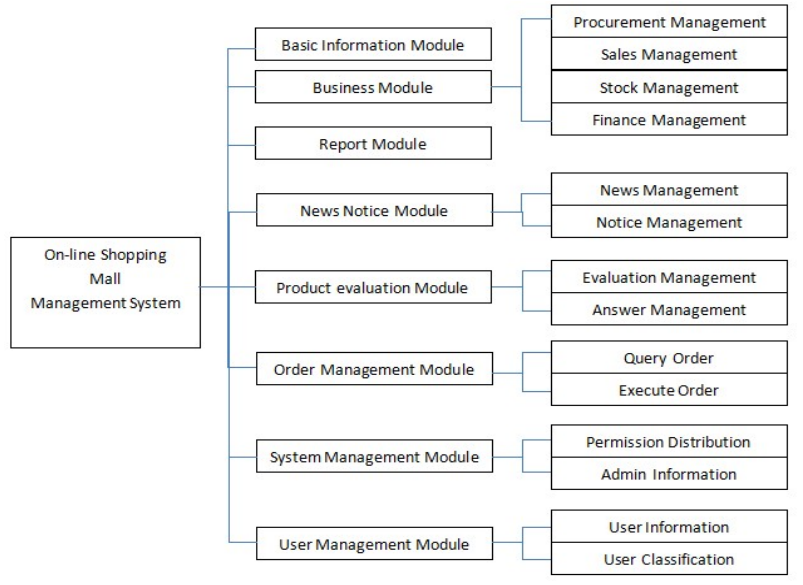

Fig 4. System module chart

The following portions are the briefly extension to the above, basic information module is mainly responsible for data backup, recovery and browse the system log. The main functions of the financial management are statistical sales revenue, expenditure, the budget, profit distribution and funds occupy, the treatment of providers paid, accounts payable and the capital turnover control are also done in this module. In addition, the financial statistics about online sales, sales calculation within day, month and season are also completed in this module. Sales management is an indispensable part of the daily operation, which fully embodies the advantages of automation, compatible with all the features of commodity management.

There are also some module functions which are described as follows, inquiries about the mall sales situation; the statistical analysis about sales and gross profit, inquires the commodity quotes, and other special treatment and discount, controlling on the sale of goods and printing the form, the inquiry about the details of the sales, new products on selves and old products off selves, and the management of commodity price and other functions.
Inventory management is mainly responsible for incoming goods, inventories revision and query, carrying out the inventory reports and so on. The functions of this module are as follows, providing timely inventory goods type, stock, quality, price, storage location and other information. According to the inventory loss, overflow and inventory management, effectively reduce the inventory loss, enhance the effective inventory, support receptionist sales, and obtains reasonable merchandise ordering cycle and quantity. Purchasing management can input, modify, query and analyze in real time, and print a variety of documents according to purchase orders, indent and returned purchase invoice. According to replenishment orders and sales situation to draw up purchasing plan and cooperate with order management department to finish distribution management and return money management.

\section{Conclusions}

J2EE three-tier structure and the current popular web application development framework are analyzed and studied, Ajax + SSH (Struts + Spring + Hibernate) framework is formed based on the techniques described above, in this paper this Ajax + SSH (Struts + Spring + Hibernate) framework is applied to B2C website background management, it has effectively changed the condition that client code is redundant, reduced the burden and later maintenance on the client, and the difficulty about expansion issues is resolved as well. In addition, it also greatly enhances the efficiency of the staff and avoids the cumbersome, messy and long cycle of In-out warehouse, and it makes that the system can quickly respond to market changes.

\section{References}

[1] (America) Marty Hall, Larry Brown. Core Servlet and JavaServer Pages: Volume 1: Core Technologies 2nd Edition [M]. PEARSON Prentice Hall, 2004.

[2] LI Gang. the actual practice of Lightweight Java EE enterprise application--Integration and development using Struts 2, Spring and Hibernate [M]. BeiJing: Electronic industry press, 2007.

[3] YANG Shaobo. J2EE Project training-- Hibernate frame technology [M]. BeiJing: Tsinghua university press, 2008.

[4] YUAN Shuai. The introduce of the business module in purchase-sellstock management system based on Java (in Chinese) [J]. China science and technology exhibition, 2008.8 .

[5] ZHAO Xiaoxia. Invoicing Management System Design and Implementation (in Chinese) [J]. Coal Technology, 129(101), Jan, 2010.

[6] LIU Bin. Proficient in Java Web integration and development: JSP+AJAX+Strust+Hibernate[M]. Electronic industry press, 2007.11.

[7] SHA Shixuan, WANG Shan. An introduction to database system (3rd Edition) [M]. Higher education press, 2000.

[8] KE Baicong. Ajax Development-conception, Case and the framework [M]. Electronic industry press, 2006.5.

[9] LI Xiaojun. The design and implementation in Electronic commerce system. BeiJing: Mechanical industry press, 2007.8.

[10] YANG Shulin, HU Jieping. The latest Java language practical case tutorial. BeiJing: Tsinghua university press, 2006.

[11] Rob Harrop, Jon Machacek. Professional development guidelines for Spring (Redsaga translation team translation). BeiJing: Mechanical industry press, 2006.8.

[12] William Crawford, Jonathan Kaplan. J2EE Design Patterns[M]. o’Reilly. 2003.9.

[13] Bruce Eckel. Thinking in Java. 3rd Edition[M]. Prentice Hall, Inc, 2003. 